\title{
Effect of cooling distance on DC-LSND treatment on weld defects and weld fractures of A-36 steel
}

\author{
Heri Wibowo ${ }^{1 *}$, M. Noer Ilman², Priyo T. Iswanto ${ }^{2}$ \\ ${ }^{1}$ Department of Mechanical Engineering Education, Universitas Negeri Yogyakarta, 55281 Yogyakarta, Indonesia \\ ${ }^{2}$ Department of Mechanical and Industrial Engineering, Gadjah Mada University, 55281 Yogyakarta, Indonesia \\ *E-mail: heri_wb@uny.ac.id \\ * corresponding author
}

Control of weld defects and weld fractures in the welding construction should be done to provide the quality assurance of the welding products and to provide a positive assessment of construction to meet technical and economic requirements. The objective of this study is to investigate the effect of the cooling distance on DC-LSND (dynamic controlled low stress no distortion) treatment on weld defects and weld fractures to obtain the best characteristic of the treatment. In this research, DC-LSND treatment was performed by cooling the both sides near weld line applied in welding process. The cooling media used cryogenic liquid nitrogen sprayed by nozzle. The nozzle was placed at a various distance behind the weld torch. Weld defect was investigated by radiograph test. Tensile strength was tested by servo pulser machine and weld fracture was examined by macro structure and SEM. Results showed that the DC-LSND treatment with a cooling nozzle that is too close to the weld torch has the potential to cause weld imperfections. Porosity and initial welding defect lead to the decrease in the tensile strength of the weld metal and the brittle fracture based on the fracture shape. SEM fractography shows that DC-LSND treatment tends to increase the number of inclusions that have an effect on increasing hardness.

This is an open access article under the CC-BY-SA license.

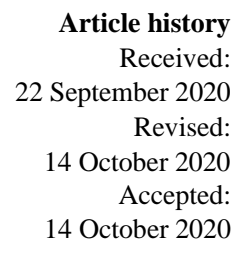

Keywords

DC-LSND treatment

Weld defect

Weld fracture

Liquid nitrogen

\section{Introduction}

Joining metals using welding technique becomes the right choice because it provides some advantages including saving production as well as operational cost, flexible in design, easy to perform and achieving the expected power. Many industries such as automotive, aircraft, and ship construction use this technique to join the components. In spite of its advantages, there are some weaknesses that need to notice including shape changes after welding (distortion), changes in micro structure due to effects of the welding heat, etc. 
Journal of Engineering and Applied Technology

Vol. 1, No. 1, March 2020, pp. 1-10

Distortion control in welding is very important, for it can decrease the quality of welding result. Control can be done by improving welding procedures or giving welding treatments. Improving welding procedures is easier in reducing distortion, but it achieves less maximal result. Distortion control with welding treatment can reduce distortion maximally, yet it needs additional tools during welding process.

Some studies related to distortion control with welding treatment are conducted, for instances: stretching welding, vibratory welding condition (VWC), static thermal tensioning (STT), transient thermal tensioning (TTT) and dynamically controlled-low stress no distortion (DC-LSND). Treatment of stretching by giving tensile effect on the work piece can reduce the distortion in plate about $60 \%$ [1]. VWC treatment with vibration effect during the welding process is also effective to reduce distortion and residual stress [2]. Treatment of static thermal tensioning (STT) [3] and transient thermal tensioning (TTT) [4] with simultaneous heat treatment of the welding process is also able to significantly reduce distortion.

Welding treatment with dynamically controlled low stress no distortion (DC-LSND) is performed by giving extreme cooling effect shortly after the work piece is welded. Some researchers report that the cryogenic cooling of CO2 in DC-LSND welding treatment reduces out of plane distortion about $81 \%$ [5]. The cryogenic nitrogen in DC-LSND welding treatment could significantly reduce the longitudinal distortion [6] [7]. However, the side effects of cryogenic $\mathrm{CO} 2$ and cryogenic nitrogen in DC-LSND treatment can cause decreasing of weld metal quality [5].

Welding quality under DC-LSND treatment needs to be controlled in order to achieve a safety guarantee as well as construction feasibility and provide a positive assessment of construction. Welding quality control can be done by examining nondestructive test to see weld imperfections such as defects, cracks, inclusions, undercut, penetration etc. In this study, the early step to detect weld quality is by analyzing the weld defects with radiographic observation followed by weld fractures analysis in the welding joint. The purpose of this research is to investigate weld defects and weld fractures to obtain the best characteristic of DC-LSND treatment in gas metal arc welding.

\section{Method}

\subsection{Materials}

This research used A36 carbon steel plates jointed by Gas Metal Arc Welding (GMAW). The plates were prepared in dimension of $400 \times 100 \times 4 \mathrm{~mm}$, grooved in one side with root pass of $2 \mathrm{~mm}$ and angle of 30o. The electrode selected to join this material was ER70S-6. The chemical compositions of A36 steel including: $\mathrm{C}=0.159 \%, \mathrm{Si}=0.243 \%, \mathrm{Mn}=0.733 \%, \mathrm{Cu}=0.013 \%, \mathrm{Ni}=0.016 \%$, $\mathrm{Cr}=0.042 \%$ and the chemical composition of ER70S-6 including $\mathrm{C}=0.116 \%, \mathrm{Si}=0.430 \%$, $\mathrm{Mn}=0.859 \%, \mathrm{Cu}=0.083 \%, \mathrm{Ni}=0.014 \%, \mathrm{Cr}=0.035 \%$.

\subsection{Welding Process}

GMAW was used to weld the plates in constant welding speed of $4.4 \mathrm{~mm} / \mathrm{s}$ and welding current 145 ampere. The ER70S- 6 electrode was selected by using $0,8 \mathrm{~mm}$ of diameter and shielded gas was 
selected by using carbon dioxide in which debit was 10 liter/minute. The DC-LSND device was installed in welding rig that simultaneously moved in welding process.

The DC-LSND treatment was performed by cooling process behind the weld arc that quickly affected the temperature decline in cooling area as shown in Fig.1. The cooling process used the cryogenic liquid nitrogen in which debit was $200 \mathrm{ml} /$ minute sprayed in weld metal area. Weld metal must be protected from negative effect of liquid nitrogen by locating a partition between the weld torch and the coolant nozzle. The distance in spraying nitrogen liquid and weld torch was varied from $15 \mathrm{~mm}, 30 \mathrm{~mm}, 50 \mathrm{~mm}$, and $70 \mathrm{~mm}$ and termed respectively with DC-LSND-15, DC-LSND-30, DCLSND-50, and DC-LSND-70.

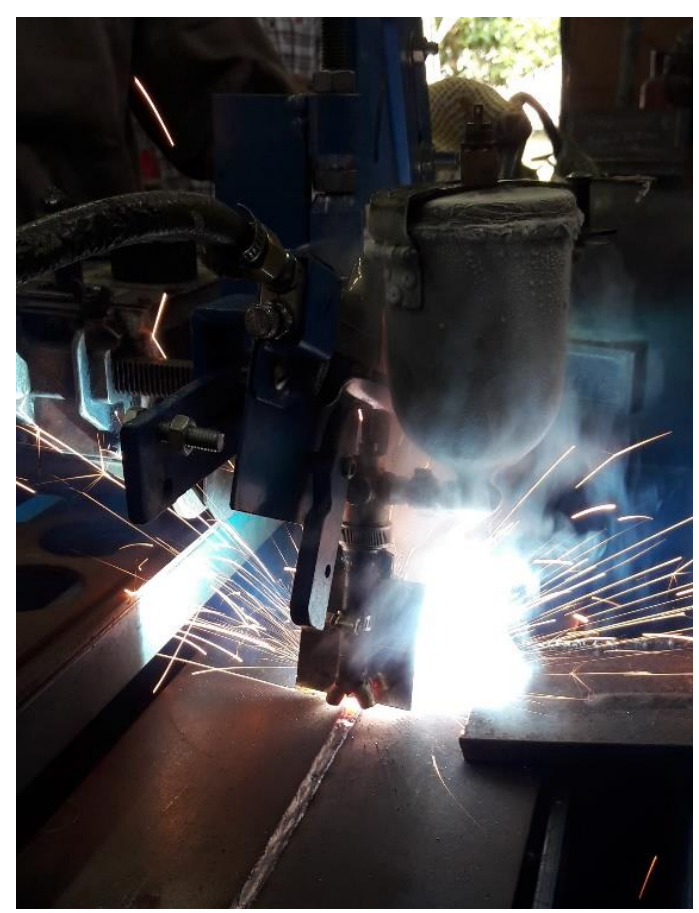

Fig.1. The process of DC-LSND treatment.

\subsection{Radiography Examination}

Three-dimensional damage of welded specimen such as wormholes and slags could be visualized as tiny cavities in a film image by radiographic testing methods. The specimen on cover side was exposed to a radiation beam, and the back side was attached to a film to take photos of X-rays.

The amount of radiation that passed to the film at a different point caused the difference level in the dark-light of the film. Since the specimen area was exposed by X-ray, the weld area emitted less radiation than the other regions. It was visualized in the film's white patch pattern. Radiographic testing used X-ray tube equipment as shown in Fig. 2. The stages of the radiographic testing process on welded specimen were listed below: 
Journal of Engineering and Applied Technology

Vol. 1, No. 1, March 2020, pp. 1-10

(1) Verifying the thickness of the plate to determine the penetrometer wire number used during the test.

(2) Determining kV (voltage) and the length of time of irradiation to be used on X-rays based on tables and calculations.

(3) Determining SFD (distance of X-ray source and specimen based on table and calculation).

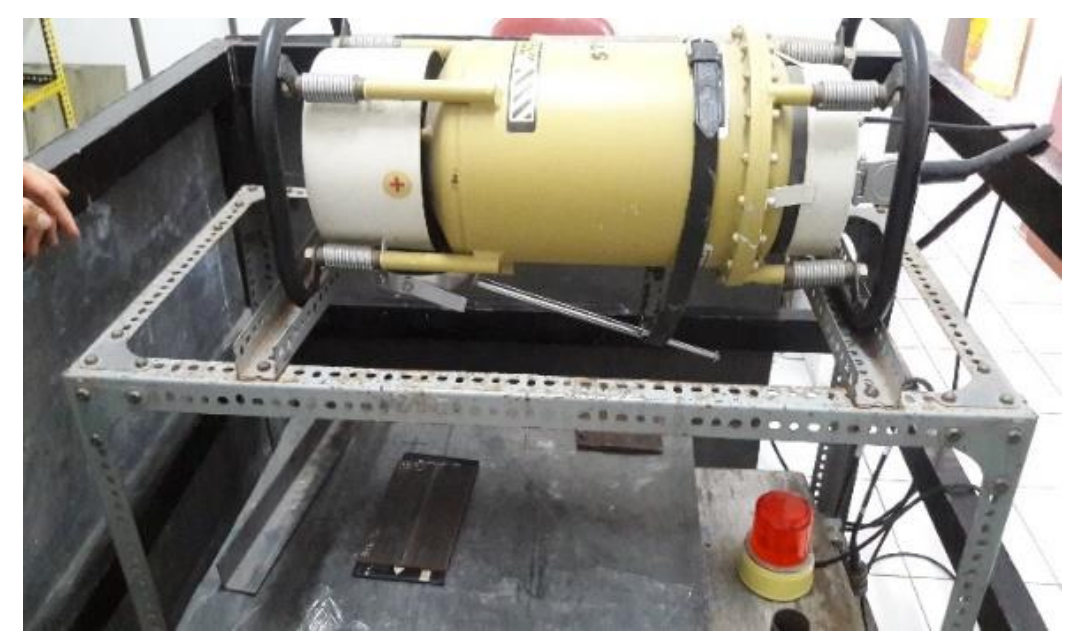

Fig. 2. Radiographic test equipment on welding specimens.

\subsection{Tensile Tests}

Tensile tests were done by using a tensile machine with a load of 2 tons on the parallel direction of the weld line. The standard guideline JIS Z2201 was used in reference to the specimen dimension as shown in Fig. 3. The result of tensile tests were maximum strength and yield strength was used to compare the strength and the fracture properties in the welding treatments.

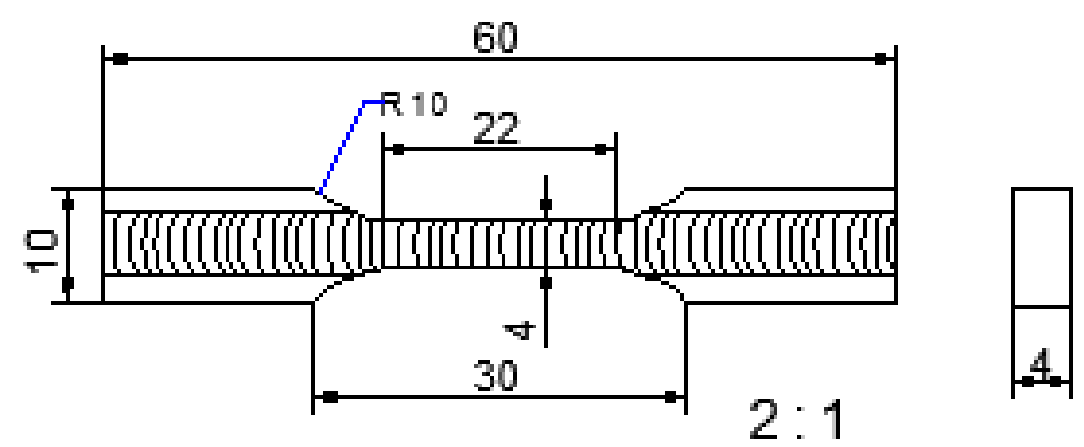

Fig. 3. Longitudinal tensile test specimen [8]. 
Journal of Engineering and Applied Technology

Vol. 1, No. 1, March 2020, pp. 1-10

\section{Results and Discussion}

\subsection{Radiographic Test}

The radiographic test is done with $\mathrm{X}$ rays which enables to display the entire inside of the weld area with a light and dark side in the film as presented in Fig. 4. Based on Fig. 4(b), it is seen that the darker side of the radiography image representing weld metal area shows a defect particularly in DC-LSND15 treatment. This defect indicates that DC-LSND treatment with cooling nozzle which are too close with weld torch $(15 \mathrm{~mm})$ is potential to cause weld imperfection.

It happens because the burst of cooling liquid disrupts protective gas of $\mathrm{CO}_{2}$, hence the function of protective metal is lost. In support of it, Chaudhari et al. [9] say that flux as weld metal protection can increase weld ability and weld penetration rate. Without the existence of flux in weld, it can result a drastic decrease of weld ability.

Fig. 4 (a), 4(c) and 4(d) show the bright side of the radiographic image which are more stable and uniform. Also, it shows stable weld metal penetration and uniformity in size and shape as well as no weld defect found. It indicates that the condition of as-welded and DC-LSND treatment within $30 \mathrm{~mm}$ and above is not potential to cause imperfection, since the small rate of disturbance from the burst of cooling liquid can be eliminated.

\subsection{Tensile Test}

The longitudinal tensile test is aiming at finding out the strength of tensile weld metal. This test is performed to weld specimen with DC-LSND treatment by varying cooling torch distance towards weld torch as presented in Fig. 5.

Fig. 5 shows that the tensile strength on the longitudinal direction tends to be the same for treatments DC-LSND-30, DC-LSND-50, DC-LSND-70 that is between $589 \mathrm{MPa}$ to $614 \mathrm{MPa}$. In the DC-LSND-15 treatment, the tensile strength tends to be lower than other DC-LSND treatments. The lowest longitudinal tensile strength is seen in the as-welded condition of $540 \mathrm{MPa}$.

Fig. 6 presents the fracture of longitudinal tensile test on: (a) DC-LSND-70, (b) DC-LSND-50, (c) DC-LSND-30, and (d) DC-LSND-15.Based on the result of the fracture in the longitudinal tensile test in Fig. 6, it shows that the DC-LSND-30, DC-LSND-50, and DC-LSND-70 treatments are ductile fractures due to large elongation before fracture, while DC-LSND-15 treatment shows brittle fracture due to small elongation before fracture. Brittle fracture of DC-LSND-15 is caused by the porosity in the weld metal as the initial crack during tensile testing.

It can be seen that the DC-LSND treatment can increase tensile strength, especially in weld metal. This is due to the DC-LSND treatment which affects the hardness level of the weld metal associated with an increase in the percentage of acicular ferrite in the weld metal as supported by Fan et al. [10] and Digheche et al. [11].

The lowest longitudinal tensile strength is seen in the as-welded condition due to the lowest hardness value associated with low acicular ferrite percentage in weld metal. 
Journal of Engineering and Applied Technology

Vol. 1, No. 1, March 2020, pp. 1-10

(a)

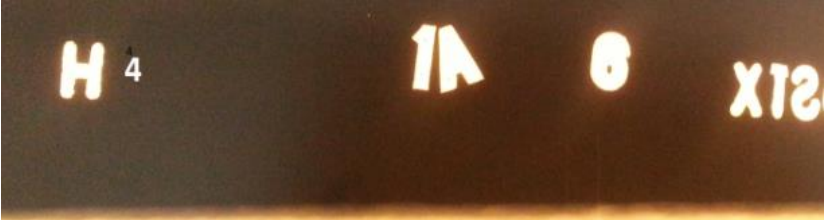

(b)

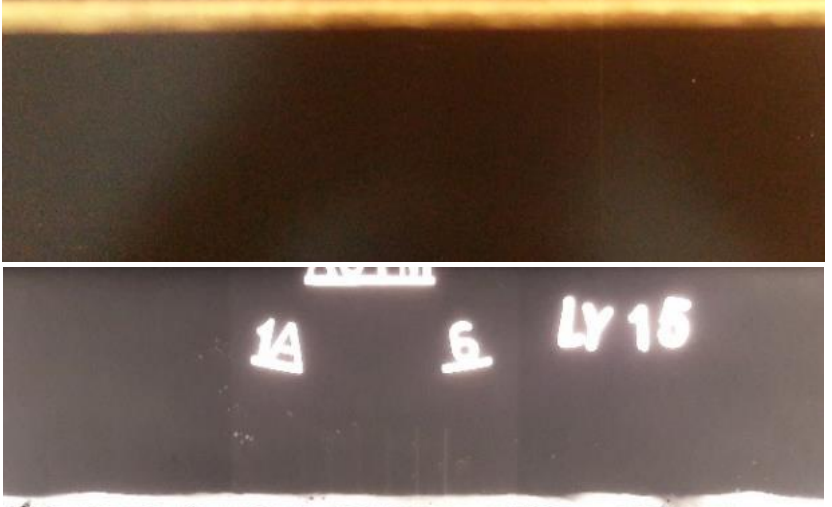

(c)

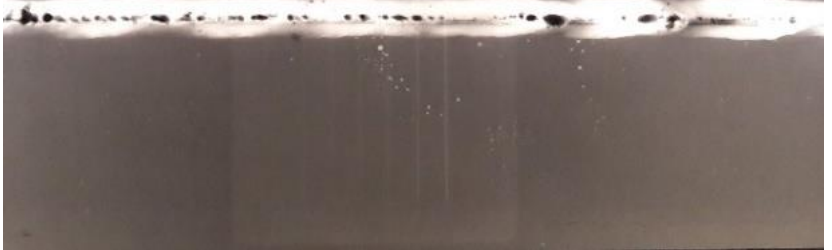

(d)

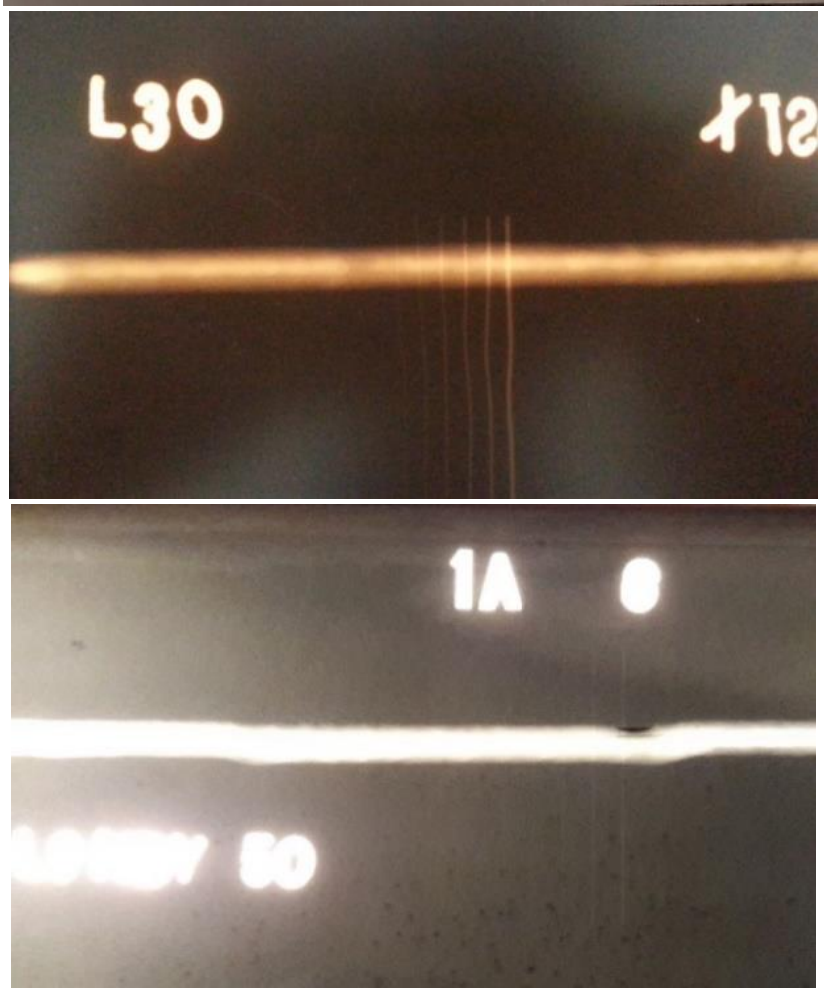

Fig. 4. Radiographic inspection on:

(a) As-welded, (b) DC-LSND-15, (c) DC-LSND-30, (d) DC-LSND-50. 


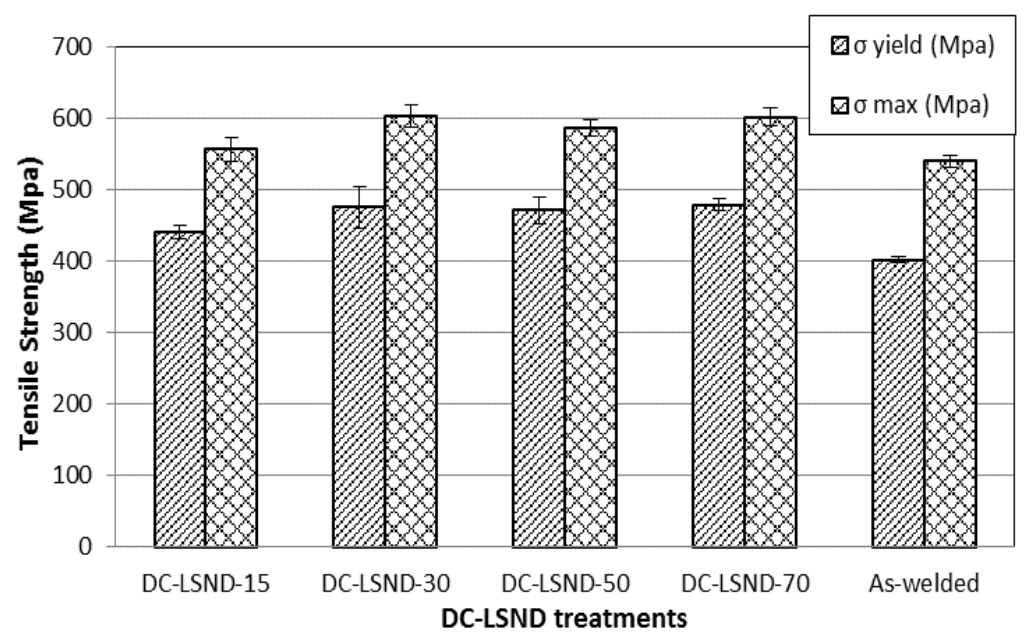

Fig. 5. Tensile strength of longitudinal direction by DC-LSND treatment.

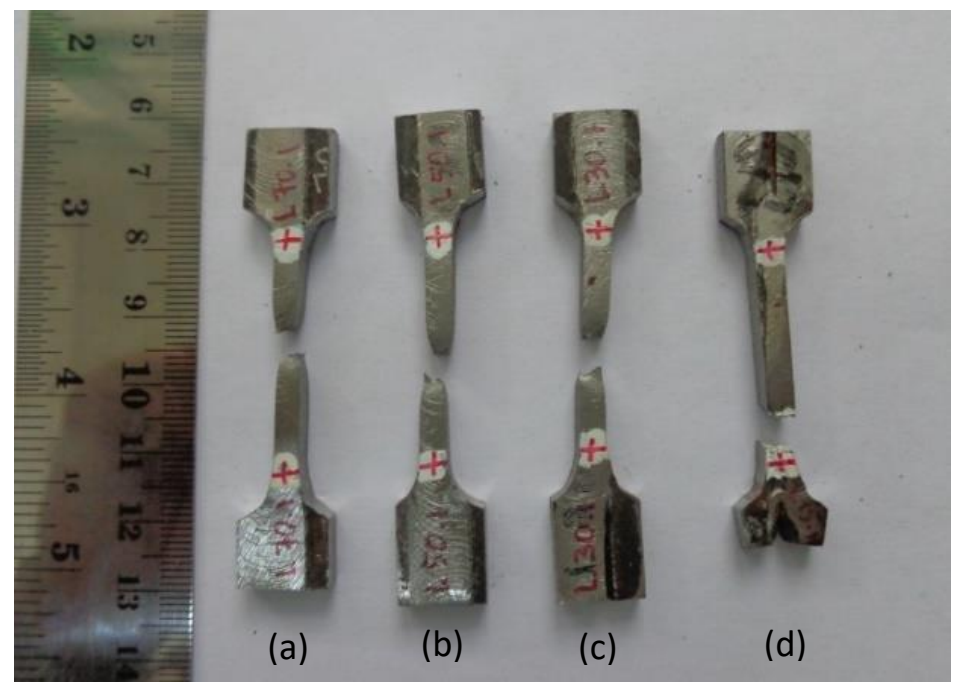

Fig. 6. Fracture of longitudinal tensile test on:

(a) DC-LSND-70, (b) DC-LSND-50, (c) DC-LSND-30, (d) DC-LSND-15.

Fig. 7 shows a cross-section of tensile test on the DC-LSND-15 and DC-LSND-30 treatments. The porosity groove on the tensile fracture is clearly visible in the DC-LSND-15 treatment which indicates that the initial crack occurs in this porosity.

When associated with a fracture cross-section, porosity specimen tends to brittle fractures occurence, while specimen without porosity tend to show ductile fractures. When associated with data of tensile strength, a decreasing of tensile strength occurs in specimen containing porosity in weld metal. Thus, porosity and initial defect in the weld metal lead to a decrease in tensile strength 
and the occurrence of brittle properties. This is because the DC-LSND coolant disrupts the function of the protective gas during the welding process.

The fracture surface was observed with SEM ranging from 500x magnification under as-welded conditions (Fig. 8.a) and 500x on the DC-LSND-30 treatment (Fig. 8.b). It shows a nearly equal to fracture surface in shape and size of concave.

However, Fig. 8.c and Fig. 8.d that compare the fracture surface at 2000x magnification shows that the DC-LSND-30 treatment has many particles in inclusions shape compared to as-welded conditions. The inclusion particle has diameter size between 0.5 to $2 \mu \mathrm{m}$. Fattahi et al. [12] state that increasing of inclusion has effected the increasing amount of acicular ferrite phase of weld metal.

(a)

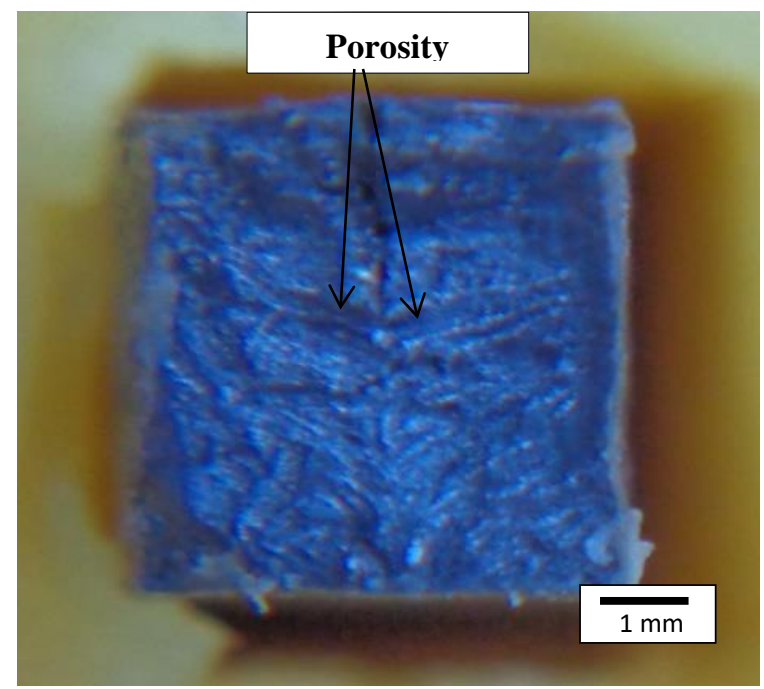

(b)

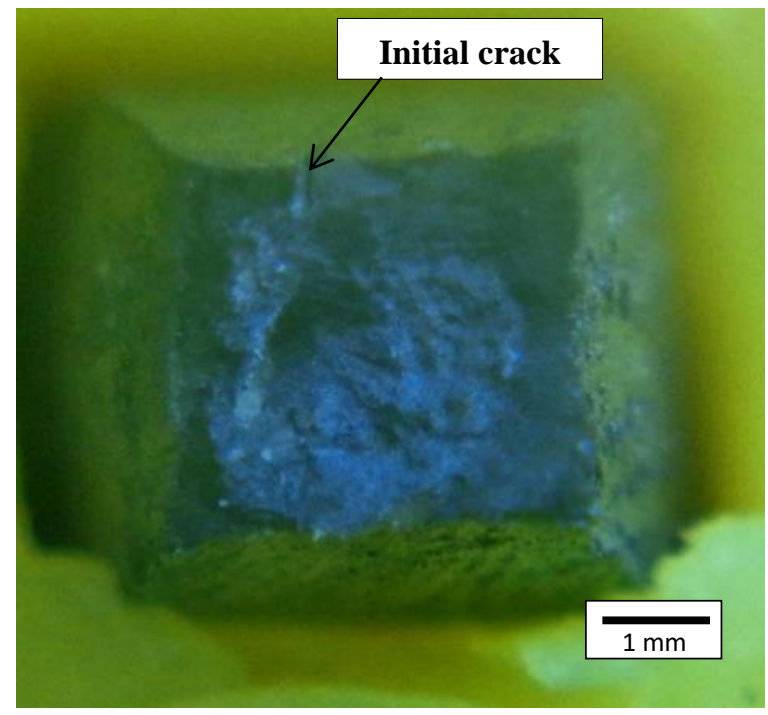

Fig. 7. Cross-section of the longitudinal tensile test on: a) DC-LSND-15, b) DC-LSND-50. 
Journal of Engineering and Applied Technology

Vol. 1, No. 1, March 2020, pp. 1-10

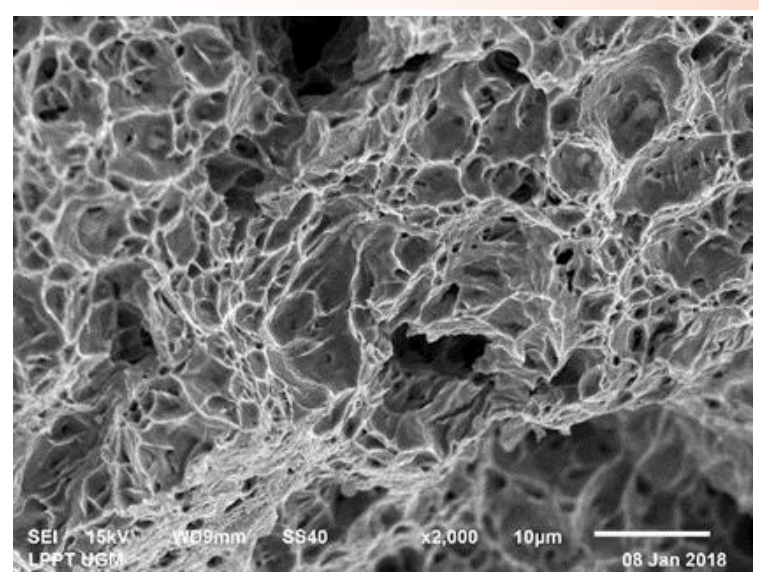

(a)

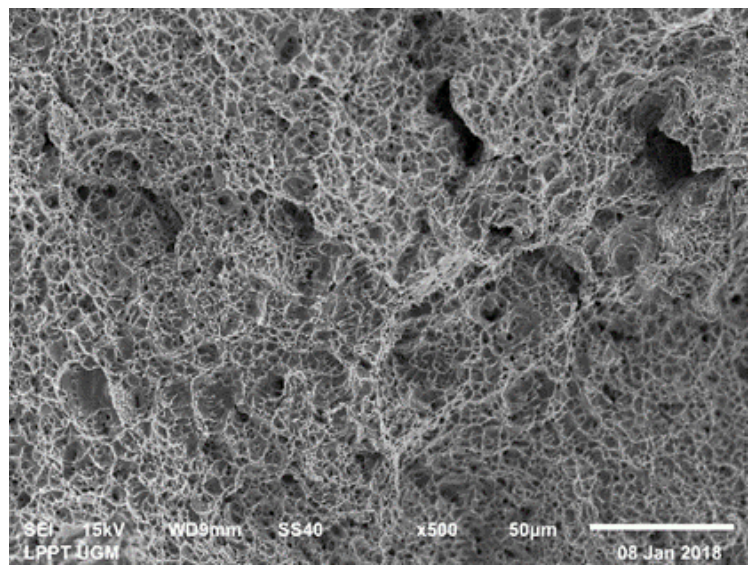

(c)

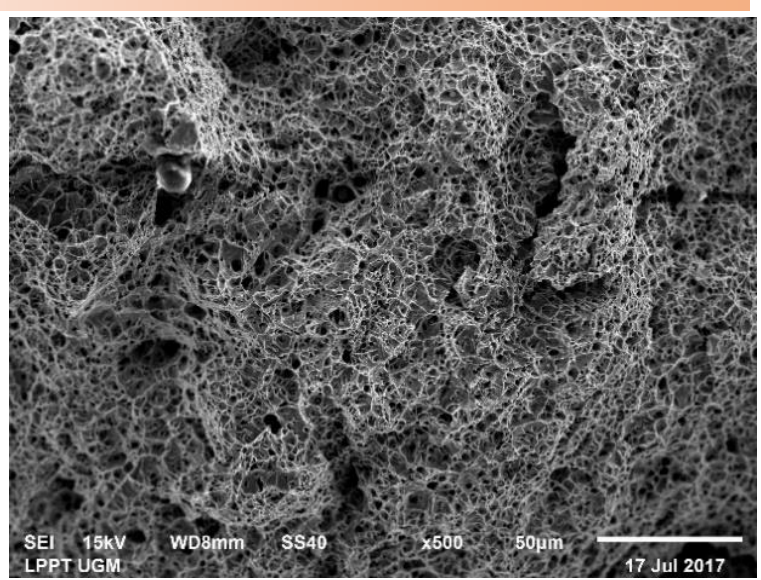

(b)

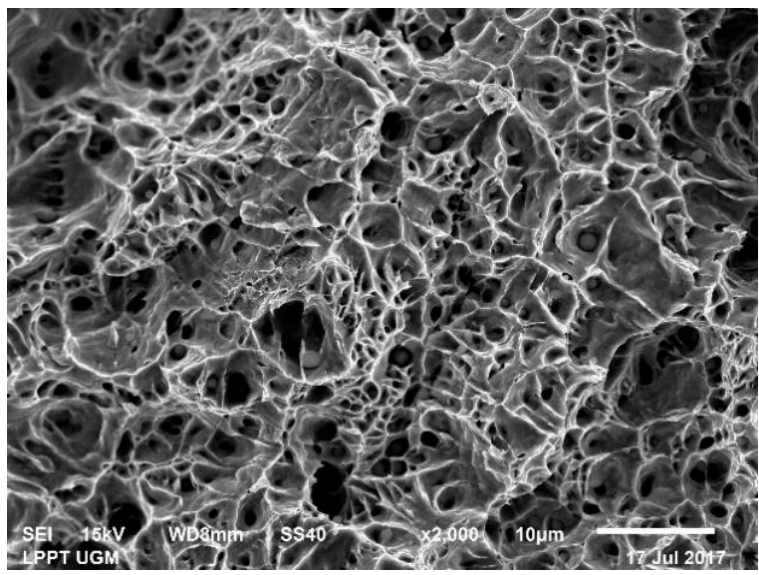

(d)

Fig.8. SEM micrographs of the fracture surface on :

(a) as-welded 500x, (b) DC-LSND-30 500x, (c) as-welded 2000x, (d) DC-LSND-30 2000x.

\section{Conclusion}

The DC-LSND treatment of GMAW welding has affected the quality and the mechanical strength of the weld. The main results are summarized as follows:

(1) The DC-LSND treatment with a cooling nozzle that is too close to the weld torch has the potential to cause weld imperfections.

(2) The brittle fracture of DC-LSND-15 is caused by the porosity of the weld metal as initial crack during tensile testing.

(3) The DC-LSND treatment can increase the tensile strength of the weld metal due to the increasing phase of the acicular ferrite and the increasing hardness of the weld metal.

(4) Increasing the percentage of acicular ferrite followed by the amount of inclusions on the weld metal results in increasing tensile strength of the weld metal. 
Journal of Engineering and Applied Technology

Vol. 1, No. 1, March 2020, pp. 1-10

\section{References}

[1] Triyono, H. Sukanto, M. Muhayat, and Sutiyono, "Effect of Stretching during Welding Process on the Weldability of Dissimillar Metals Resistance Spot Welded between Carbon Steel and Low Nickel Stainless Steel," Adv. Mater. Res. J., vol. 894, pp. 206-211, 2014.

[2] J. Xu, L. Chen, and C. Ni, "Effect of vibratory weld conditioning on the residual stresses and distortion in multipass girth-butt welded pipes," Int. J. Press. Vessel. Pip., vol. 84, no. 5, pp. 298-303, May 2007.

[3] M. N. Ilman, M. R. Muslih, N. Subeki, and H. Wibowo, "Mitigating distortion and residual stress by static thermal tensioning to improve fatigue crack growth performance of MIG AA5083 welds," Mater. Des., vol. 99, pp. 273-283, 2016.

[4] J. Souto, E. Ares, and P. Alegre, "Procedure in reduction of distortion in welding process by high temperature thermal transient tensioning," Procedia Eng., vol. 132, pp. 732-739, 2015.

[5] R. Holder, N. Larkin, L. Kuzmikova, L. Huijun, Z. Pan, and N. J, "Development of a DCLSND welding process for GMAW on DH-36 Steel," 56th WTIA Annu. Conf., vol. 2011, pp. 1-13, 2011.

[6] R.S. Sudheesh and Siva N. Prasad, "Parametric Studies on Effect of Trailing Liquid Nitrogen Heat Sink on TIG Welding of Steels," Adv. Mater. Res. . 2014, vol. 875, no. February, pp. 1595-1599, 2014.

[7] S. R. Kala, N. Siva Prasad, and G. Phanikumar, "Studies on multipass welding with trailing heat sink considering phase transformation," J. Mater. Process. Technol., vol. 214, no. 6, pp. 1228-1235, 2014.

[8] H. Wibowo, M. N. Ilman, P. T. Iswanto, and M. R. Muslih, "Control of Distortion by Combined Effect of DC- LSND and TTT in MIG Weld Joints and Its Effect on Residual Stress and Fatigue Behavior," Int. J. Mech. Mechatronics Eng., vol. 17, no. 6, 2017.

[9] P. G. Chaudhari, P. B. Patel, and J. D. Patel, "Evaluation of MIG welding process parameter using Activated Flux on SS316L by AHP-MOORA method," Mater. Today Proc., vol. 5, no. 2, pp. 5208-5220, 2018.

[10] L. Fan, D. Zhou, T. Wang, S. Li, and Q. Wang, "Materials Science \& Engineering A Tensile properties of an acicular ferrite and martensite / austenite constituent steel with varying cooling rates," Mater. Sci. Eng. A, vol. 590, pp. 224-231, 2014.

[11] K. Digheche, Z. Boumerzoug, M. Diafi, and K. Saadi, "Influence of Heat Treatments on the Microstructure of Welded Api X70 Pipeline Steel,” Acta Metall. Slovaca, vol. 23, no. 1, p. 72, 2017.

[12] M. Fattahi, N. Nabhani, M. Hosseini, N. Arabian, and E. Rahimi, "Effect of Ti-containing inclusions on the nucleation of acicular ferrite and mechanical properties of multipass weld metals," Micron, vol. 45, pp. 107-114, 2013. 